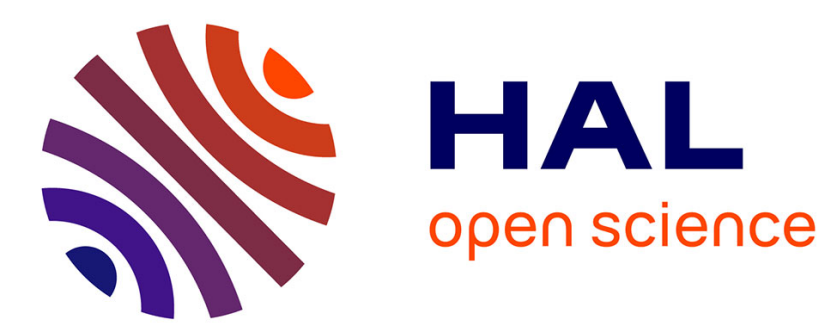

\title{
Learning-by-doing and the Costs of a Backstop for Energy Transition and Sustainability
}

Pierre-André Jouvet, Ingmar Schumacher

\section{To cite this version:}

Pierre-André Jouvet, Ingmar Schumacher. Learning-by-doing and the Costs of a Backstop for Energy

Transition and Sustainability. 2011. hal-00637960

\section{HAL Id: hal-00637960 \\ https://hal.science/hal-00637960}

Preprint submitted on 3 Nov 2011

HAL is a multi-disciplinary open access archive for the deposit and dissemination of scientific research documents, whether they are published or not. The documents may come from teaching and research institutions in France or abroad, or from public or private research centers.
L'archive ouverte pluridisciplinaire HAL, est destinée au dépôt et à la diffusion de documents scientifiques de niveau recherche, publiés ou non, émanant des établissements d'enseignement et de recherche français ou étrangers, des laboratoires publics ou privés. 


\title{
ECOLE POLYTECHNIQUE
}

CENTRE NATIONAL DE LA RECHERCHE SCIENTIFIQUE

\section{LEARNING-BY-DOING AND THE COSTS OF A BACKSTOP FOR ENERGY TRANSITION AND SUSTAINABILITY?}

\author{
Pierre-André JOUVET \\ Ingmar SCHUMACHER
}

October 2011

Cahier $n^{\circ}$ 2011-22

\section{DEPARTEMENT D'ECONOMIE}

Route de Saclay

91128 PALAISEAU CEDEX

(33) 169333033

http://www.enseignement.polytechnique.fr/economie/

mailto:chantal.poujouly@polytechnique.edu 


\title{
Learning-by-doing and the Costs of a Backstop for Energy Transition and Sustainability
}

\author{
Pierre-André Jouvet* Ingmar Schumacher ${ }^{\dagger}$
}

October 24, 2011

\begin{abstract}
We assess the impact of being able to substitute an unlimited but costly energy substitute (like wind, solar) for a non-renewable resource (like oil, coal) in a model of sustainable growth. The prospects for sustainability on the optimal path depend crucially on the costs of this substitute.Furthermore, the poorer a country, measured in terms of capital stock at a given point in time, the later it should switch to the renewable substitute, and the more likely it will be unsustainable. Taking learning-by-doing in account, we find that this leads to an earlier switching time but does not guarantee sustainability.
\end{abstract}

JEL Classification: Q21, Q32, Q42, Q56.

Key words: backstop technology; non-renewable resource; resource substitution; sustainability; learning-by-doing.

\footnotetext{
*EconomiX, University of Paris Ouest and Climate Economics Chair, e-mail: pjouvet@u-paris10.fr.

${ }^{\dagger}$ Banque centrale du Luxembourg, 2, boulevard Royal, L-2983 Luxembourg, Luxembourg, email: ingmar.schumacher@bcl.lu.

We are grateful to Katheline Schubert for discussions and thank two anonymous referees as well as the editor for their comments. The views and opinions expressed here do not necessarily reflect those of the Banque centrale du Luxembourg.
} 


\section{Contents}

1 Introduction 3

2 Empirical motivations 6

2.1 The notion of sustainability $\ldots \ldots \ldots \ldots \ldots \ldots$

3 The Benchmark Model 10

3.1 The role of the backstop technology . . . . . . . . . . . . 13

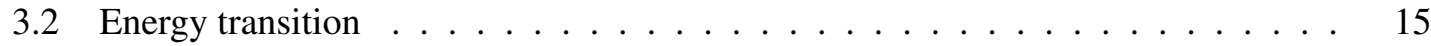

3.3 Impact on weak sustainability $\ldots \ldots \ldots \ldots \ldots \ldots$

4 The impact of learning-by-doing $\quad 18$

4.1 Energy transition . . . . . . . . . . . . . . . . . . . . . . 19

4.2 Impact on weak sustainability $\ldots \ldots \ldots \ldots \ldots \ldots$

5 Tying in with integrated assessment models 22

6 Conclusion $\quad 24$

7 Appendix 26

8 Figures $\quad 34$ 


\section{Introduction}

Given that we live in a world where most countries rely on energy inputs that are essential but nonrenewable, how does the cost of a potential energy backstop technology (like solar or wind energy) affect the optimal transition between these energy inputs? How does the optimal switching time depend on a country's capital stock? Furthermore, does the possibility of technological change through learning-by-doing affect the optimal transition date? For which countries is this the most relevant? When is sustainability along the optimal path guaranteed? These are the questions that we address here. In order to approach these questions we make use of the literature on backstop technologies and sustainability.

With respect to the backstop technology, our modeling approach builds upon Heal [23] and the subsequent line of literature (Clark [10], Hanson [22], Tahvonen and Salo [55], Tsur and Zemel [56], [57]). Heal [23], Clark [10] and Hanson [22] consider a Ramsey-type economy where production uses capital and energy as complementary inputs. Energy may either come from a non-renewable resource that is subject to extraction costs which are increasing in the amounts already extracted, or from a backstop technology that comes at a high but constant marginal cost. This literature discusses Hotelling's Rule [25] and questions whether, on an optimal path, scarcity rent (price minus marginal extraction cost) should grow over time at the discount rate or whether it should decline. We, however, abstract from extraction costs of the non-renewable resource which allows us to focus more closely on the role that the cost of the backstop technology plays for the optimal switch to the energy substitute and sustainability. We, thus, deal with backstop technologies that are already available but not yet commercially attractive enough due to their higher relative price (like solar and wind energy).

The analysis in Tahvonen and Salo [55] is more closely related to ours. They allow for increasing costs in both the non-renewable resource and the energy substitute at the expense of being able to study more fully the role of the cost of the backstop technology. In contrast to Tahvonen and Salo [55], we show that the non-renewable resources depletion may be non-monotonic ${ }^{1}$ and that it is not optimal to use both non-renewable resources and the costly substitute simultaneously. Indeed, our assumptions imply that the non-renewable resource should have been fully depleted

\footnotetext{
${ }^{1}$ This result has, in a different setting, also been obtained in Slade [50].
} 
when it becomes efficient to shift to the costly substitute. This arises since in our setting the two energy inputs are not used simultaneously since only the resource that comes at the lowest social cost will be used. We would argue that this result more accurately reflects reality since, firstly, backstops (solar or wind energy) nowadays only represent a marginal fraction of overall energy inputs and, secondly, since without the sufficient amount of subsidies these backstops would still have a too high relative price. This suggests that backstops, in a competitive, undistorted environment, would currently not be used. ${ }^{2}$ One can view our model as a special case of Tahvonen and Salo [55], where extraction costs are of a significant size. This assumption allows to obtain additional conclusions. For example, our assumptions allow us to study the timing of the switch to the energy substitute more closely. We find that the switching time increases convexly with the cost of the substitute and also crucially depends on the initial capital stock.

Tsur and Zemel [56] study the optimal transition from a non-renewable resource with increasing extraction costs to a backstop technology. Like us, they allow for learning-by-doing in the cost of the substitute. They maximize the net social benefit, which is increasing in the amount of resources used and decreasing in the costs and the extraction of the resources. The main difference to their approach is that we study the control problem in a model more in line with the approach of Heal [23]. We have a benevolent social planner who maximizes utility of consumption subject to the economy resource constraint, which allows for an important trade-off that leads to qualitatively different results compared to Tsur and Zemel [56]. This setting is then similar to Tsur and Zemel [57], who, instead of studying learning-by-doing as a means of reducing the cost of the backstop technology, study R\&D efforts. ${ }^{3}$

In the case of cost reductions via learning-by-doing we do not recover Tsur and Zemel's [56] result, which is that $\mathrm{R} \& \mathrm{D}$ activities should be undertaken directly at the maximal affordable rate. Instead, we show the following. Learning-by-doing implies that the backstop technology will be used earlier than if costs are exogenously given. In fact, the lower the cost of the backstop technology, the faster should we substitute to the energy substitute. This is in line with the simulations in Chakravorty et al. [8], who simulate a model with a partial equilibrium demand curve where

\footnotetext{
${ }^{2}$ Apart from some countries that hold strong comparative advantages in the backstop, like e.g. hydro energy in Switzerland, this argument should hold in general.

${ }^{3}$ Other approaches to technical change and resource extraction are, for example, Grimaud and Rouge [18], PerezBarahona and Zou [37] or Boucekkine and Pommeret [5].
} 
photovoltaic serves as a backstop technology for different types of non-renewable resource inputs. Furthermore, we find a trade-off between the initial capital stock and the cost of the backstop. In effect, poorer countries should substitute to the backstop technology at a later point in time compared to rich countries. ${ }^{4}$

Our work is also related to the research that deals with backstop technologies from a sustainability perspective. Solow [52], Dasgupta and Heal [13] and [14] have mainly influenced recent research on the economics of sustainability by initiating the work on backstop technologies. These articles point out that, in the absence of a backstop technology, without technical change and with capital and the non-renewable resource being complements in production, we would see an unsustainable evolution of consumption over time. Including a backstop technology into the above framework, we notice that the cost of the energy substitute is crucial for the sustainability of consumption and show under what conditions optimal consumption may be non-declining. Too large costs of the backstop technology will lead to an optimal path that is not sustainable, whereas sufficiently small costs will allow for optimal paths that are sustainable. Then we investigate the role of learning-by-doing in the energy substitute for the sustainability of consumption and the transition between the resources. Our result is that learning-by-doing may help sustainability but it does not guarantee it.

Additional research has looked at particular aspects of backstop technologies that are clearly important but that we mention for completeness only. In the case of uncertainty over the date when a potential backstop technology is discovered, Dasgupta and Heal [13] find that an optimal policy should be to extract the non-renewable resource in a qualitatively equivalent way to the case without a backstop technology but to use a higher discount rate which reflects the probability of discovering the backstop technology. Though this is clearly relevant for technologies like fusion, where we hold uncertainty over the date at which we can finally use this technology, it is less relevant for solar or wind energy, which currently already exist but at a too high relative cost. Powell and Oren [39] derive how a planner would invest in backstop capacity when choosing between the use of a non-renewable input in production and a backstop (see also Wirl [61]). Just et al. [29] study the optimal timing of investing in $R \& D$ if there is uncertainty over the length of time needed

\footnotetext{
${ }^{4}$ This result is closer to Tsur and Zemel [57].
} 
to develop a backstop technology. Chang and Young [9] illustrate some perspectives of major oil firms on future energy developments. Growiec and Schumacher [20] study how technological change in the substitutability between non-renewable and renewable resources in production can lead to an endogenous emergence of the renewable resource as a backstop technology. There is also a considerable and growing literature dealing with backstops and polluting non-renewable resources. Aronsson et al. [2], Gjerde et al. [16] and more recently Tsur and Zemel [59] and [58] underline the energy trade-offs under the risk of catastrophic events. Other studies on backstop technology include Tahvonen [54], who studies how a non-polluting backstop technology should substitute a pollution non-renewable resource. Schumacher [47] studies how the trade-off between a polluting non-renewable resource and a renewable one is affected by pollution that may induce an irreversible catastrophe.

The article is organized as follows. Section 2 introduces further empirical motivations and provides the definition of sustainability that we use throughout this article. In section 3 we develop the benchmark model with an exogenous cost of the substitute and the backstop technology effect. We analyze the conditions for the resource use, the transition between resources and the sustainability of consumption. In section 4 we introduce endogenous learning-by-doing and compare the results to the exogenous cost case. Section 5 discusses our results in the light of some of the results obtained in the integrated assessment modeling literature. Section 6 concludes.

\section{Empirical motivations}

There are two general questions which one could argue lie at the heart of modern environmental economics: energy security and the costs of climate change from fossil energy use. The debate on energy security has mainly been centered around the question of how a society can have a sustainable consumption paths if it, in its energy needs, so exclusively relies on limited and exhaustible fossil fuels (oil, natural gas, and coal). For example, the World Energy Outlook [32] writes that fossil fuels represent nearly 80 percent of world primary energy consumption. Add to this another $7 \%$ from the possibly limited ${ }^{5}$ nuclear sector, another approximately $9 \%$ from an unsustainable

\footnotetext{
${ }^{5}$ Some research suggests that too few uranium resources exist to meet demand in the future (IAEA [26]).
} 
use of traditional biomass and we quickly arrive at a number which is only marginally different from $100 \%$. The relevant question thus is: How long can we continue like we do now? Figure 1 shows the cumulative consumption ${ }^{6}$ of gas, oil and coal from 1751 to 2005 . We observe convex increases with the fastest growth in oil. The horizontal lines show the currently-known global stock of the three types of fossil fuels and the arrows pointing at each line correspond to the expected exhaustion time, which we obtained through an extrapolation based on the historical series. ${ }^{7}$ Given these estimates we see that oil may already be depleated in 2048 , closely followed by gas in the year 2063 and later by coal in 2239 . With the currently $1.5 \%$ annual increase in

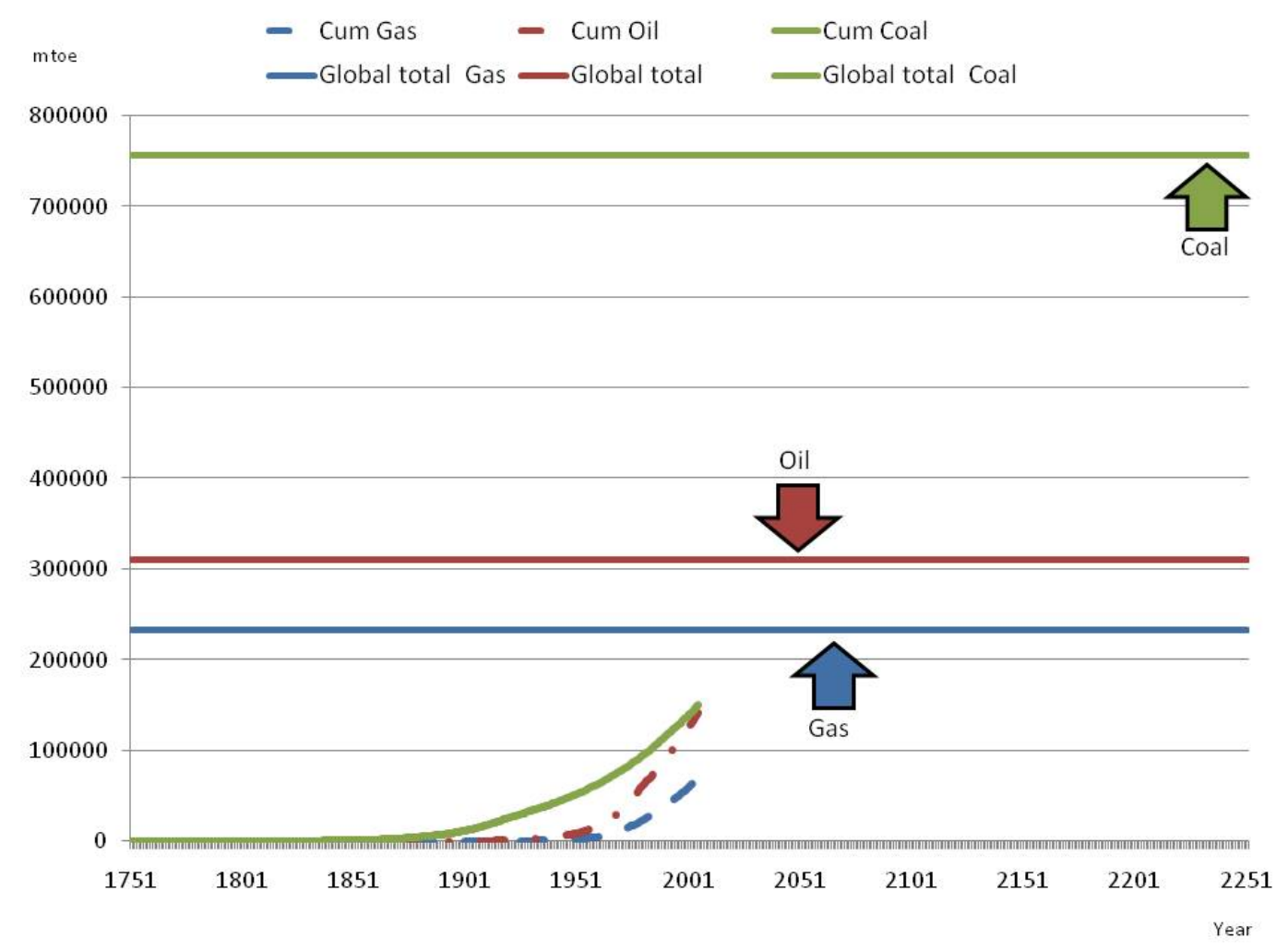

Figure 1: Cumulative consumption of fossil fuels 1751-2005

\footnotetext{
${ }^{6}$ The plot is constructed from data from the Carbon Dioxide Information Analysis Center (CDIAC) on CO2 emissions from fossil fuels for 1751 to 2005. Using the data for the consumption from fossil fuels from 1980 to 2005 from the BP Statistical Review of World Energy 2008 we then regressed the CO2 data on the consumption data and by simple extrapolation were able to estimate the approximate consumption of fossil fuels from the CO2 data. Due to the generally linear relationship this method is valid.

${ }^{7}$ We used a rather mechanical method by fitting a Gompertz function for time on the consumption of fossil fuels from various dates onwards which allows a rough estimate of the time when fossil fuels will be exhausted given current trends continue. The exhaustion estimates correspond to the 'reasonable' case scenarios where we only use data from 1980 onwards which reflects better the later technological improvements. Similar estimates, with less crude methods, are in Shafiee and Topal [49], see also Schmalensee et al. [45].
} 
primary energy consumption we will see a doubling of energy demand until 2040 and a threefold increase until 2060. Without a considerable change in consumption and production habits, we are very likely steering towards a scenario where society suddenly has to cope with a world in which the non-renewable resources will be depleted and energy demand may not be met. This rather likely scenario will lead to a situation where the developing world will face tremendous problems to meet basic needs and where the developed world will have to change its social and productive structures to accomodate this situation. Thus, given the exhaustible resources are an essential input to production as is clearly the case, then what are our options?

Surprisingly, the same person who helped us in designing a world based on fossil fuels was also the one who saw the limitations of the world that he basically created: Thomas Edison. Already in 1931, Thomas Edison told his friends Henry Ford and Harvey Firestone: "I'd put my money on the sun and solar energy. What a source of power! I hope we don't have to wait until oil and coal run out before we tackle that." The only question that Thomas Edison did not settle down to answer is how much money should and can be put aside for these alternative energies and as to when we should substitute towards the alternative energy.

At the moment, alternative energies (biomass, geothermal, wind, solar, and hydropower) contribute around $4 \%$ to overall energy consumption. The main reason ${ }^{8}$ for this somewhat low usage of renewables is that their price relative to the virtually free non-renewable resources is significantly higher. The World Energy Outlook suggests that fossil fuels are still expected to account for approximately $85 \%$ of energy demand in 2030 . However, we have also see an increasing international effort to find solutions for this problem. One prominent example is the Renewable Energy Task Force by the Group of Eight (G8) in 2000 which emphasizes the need to reduce costs of alternative energies by expanding markets. At the same time we observe reductions of 10 to 20 percent in production costs for each cumulative doubling of production in photovoltaics and wind technologies, attributable to economies of scale and learning-by-doing. Overall one can say that the substitution of alternative energy sources for fossil energy seems globally feasible, but current

\footnotetext{
${ }^{8}$ Another reason is that the prospects for increases in certain alternative energies seem limited. For example, hydropower is believed to have reached its maximum economic capacity in the developed world and is believed to have limited applicability in the developing one due to high costs and property right problems. Furthermore, alternative energy sources are often strongly limited by their geographical nature since they require specific geographical characteristics which are not available in every region.
} 
costs are still too high in order to continue our present lifestyle.

As a preliminary conclusion, we thus observe that relying on fossil energy will lead to an unsustainable future. At the same time, if we were to substitute to the currently more expensive alternative energy inputs like photovoltaics and wind energy, then we would almost surely see substantial GDP losses simply due to the presently higher costs of these alternative energies. Whether and when this substitution will allow for a sustainable consumption level is one of the important questions that we address in the remainder of this article.

\subsection{The notion of sustainability}

Whenever we refer to sustainability, we mean Sustainable Development, which defines sustainability as non-declining consumption (Daly [11], Pezzey [38]). In our approach non-declining consumption is equivalent to non-declining utility. Indeed, we assume that individuals are only concerned with their level of consumption and we neglect other variables like pollution or amenity value from decreasing natural capital. Even if pollution and the damaging aspects thereof are sometimes considered as an important reason to adopt backstop technologies, we want to focus only on the optimal consumption path and on the scarcity effects rather than the polluting nature of the non-renewable resource. ${ }^{9}$ This particular focus allows us to draw conclusions that go somewhat beyond those that had been reached up to now. Therefore, we consider a 'weak sustainability' framework as is present in Pezzey's [38] work. We shall be concerned with sustainability along the optimal consumption path without introducing sustainability as a constraint. In that sense we follow Anand and Sen's [1] recommendation to capture issues of resource dependence in the growth problem and then ask whether optimal growth has the property of sustainability. ${ }^{10}$ Our argument for this is as follows. If, indeed, an optimal path achieves sustainability by relying on the preferences of the representative agent without the need to introduce other ethical considerations (which might, for example, not fully correspond to the preferences of the agents), then this would correspond to a sustainable first-best result. Our intention is to understand how and when

\footnotetext{
${ }^{9}$ Relevant articles that study the role of pollution in the utility function are Schou [46], policy implications are drawn in Grimaud and Rougé [19], while John and Pecchenino [27] study an overlapping generations model with pollution and Schumacher and Zou [48] study the role of pollution perception.

${ }^{10} \mathrm{~A}$ complementary approach is given in Endress and Roumasset [15], who analyze the impact of the cost of the backstop technology on the golden rule and maximin consumption level in a model similar to Heal [23].
} 
this sustainable first-best result might be achieved.

\section{The Benchmark Model}

Our modeling approach here closely follows the one in Heal [23] but excludes extraction costs of the non-renewable resource. ${ }^{11}$ This allows to focus more extensively on the role that the cost of the energy substitute plays. We then extend Heal's analysis by allowing for technical change in the cost of the renewable resource substitute.

The social planner ${ }^{12}$ solves the subsequent optimal control problem ${ }^{13}$

$$
\max _{\{C(t), R(t), M(t)\}} W=\int_{0}^{\infty} e^{-\rho t} u(C(t)) d t
$$

subject to

$$
\begin{aligned}
\dot{K}(t)= & F(K(t), R(t)+M(t))-C(t)-\gamma M(t), \\
\dot{S}(t)= & -R(t), \\
& C(t), K(t), S(t), R(t), M(t) \geq 0, \\
& K(0), S(0) \text { given. }
\end{aligned}
$$

Here, consumption at time $t$ is represented by $C(t)$; capital by $K(t)$; the flow of non-renewable resources by $R(t)$ and the stock thereof by $S(t)$; the costly substitute by $M(t)$ with price $\gamma$; $u(C(t))$ is the utility function ${ }^{14} ; \rho>0$ the discount rate and $Y(t)=F(K(t), R(t)+M(t))$ is the production function for capital accumulation. As a matter of convenience, we exclude capital depreciation for simplicity and without an important loss of generality. We impose the following

\footnotetext{
${ }^{11}$ An alternative assumption is to consider that extraction costs for non-renewable resources are always lower than the cost of the energy substitute.

${ }^{12}$ In our framework, we depart somewhat from Anand and Sen [1] but conserve the seminal setting of Solow [51] and Dasgupta and Heal and [13] [14]. Stern [53] discusses the impact of approximately zero utility discounting for global warming and Dasgupta [12], by incorporating ethics into benefit-cost analysis, follows the same approach. In our model, the discount rate can be as small as possible but positive, so an approximately zero utility discounting can be possible as long as the discount rate remains strictly positive and utility is bounded.

${ }^{13}$ In terms of notation, for any variable $z(t)$ we use $\dot{z}(t) \equiv d z(t) / d t, \hat{z}(t) \equiv \dot{z}(t) / z(t)$, and we denote the partial derivative of a function $G(z, y)$ with respect to $z$ by $G_{z}$.

${ }^{14}$ We consider a given utility function, for uncertainty about future preferences we refer the reader to Ayong Le Kama and Schubert [4].
} 
assumptions.

Assumption 1: The utility function $u: \mathbb{R}_{+} \rightarrow \mathbb{R}$ is at least twice continuously differentiable and has the standard properties of $u_{C}>0, u_{C C}<0 \forall C$. We assume $\lim _{C \rightarrow 0} u_{C}=+\infty$.

Assumption 2: The production function $F: \mathbb{R}_{+}^{2} \rightarrow \mathbb{R}_{+}$is concave in both arguments with $F_{K} \geq 0$ and $F_{R} \geq 0$, and verifies $F(0, R+M)=F(K, 0)=0$.

An admissible path is defined as a trajectory $\{C(t), K(t), R(t), M(t), S(t)\}_{0 \leq t \leq \infty}$ which meets the constraints (2) and (3) with the states $K(t)$ and $S(t)$ being piecewise continuous and the controls $C(t), R(t), M(t)$ piecewise continuous. We then define the path given by the trajectory $\left\{C(t)^{*}, K(t)^{*}, R(t)^{*}, M(t)^{*}, S(t)^{*} ; t \geqslant 0\right\}$ as an optimal path if it is admissible and $\forall\{C(t), K(t), R(t), M(t), S(t) ; t \geqslant 0\}$ admissible paths we have $\int_{0}^{\infty} e^{-\rho t} u\left(C(t)^{*}\right) d t \geq \int_{0}^{\infty} e^{-\rho t} u(C(t)) d t$.

The optimization problem can be rewritten in Lagrangian form as follows:

$$
\mathcal{L}(t)=\mathcal{H}(t)+\omega_{R}(t) R(t)+\omega_{M}(t) M(t),
$$

where $\mathcal{H}(t)$ is the current value Hamiltonian and given by

$$
\mathcal{H}(t)=u(C(t))+q(t)(F(K(t), R(t)+M(t))-\gamma M(t)-C(t))-\lambda(t) R(t),
$$

where $q(t)$ is the shadow value of capital and $\lambda(t)$ the one of the non-renewable resource. The first order conditions give us

$$
\begin{aligned}
u_{C} & =q(t), \\
q(t) F_{R}-\lambda(t)+\omega_{R}(t) & =0, \\
q(t)\left(F_{R}-\gamma\right)+\omega_{M}(t) & =0, \\
-q(t) F_{K} & =\dot{q}(t)-\rho q(t), \\
\rho \lambda(t) & =\dot{\lambda}(t) .
\end{aligned}
$$


The complementarity slackness conditions are given by

$$
\begin{gathered}
\omega_{R}(t) R(t)=0, \quad R(t) \geq 0, \quad \omega_{R}(t) \geq 0 \\
\omega_{M}(t) M(t)=0, \quad M(t) \geq 0, \quad \omega_{M}(t) \geq 0 .
\end{gathered}
$$

Finally, the transversality conditions read

$$
\begin{aligned}
\lim _{t \rightarrow \infty} q(t) K(t) e^{-\rho t} & =0, \\
\lim _{t \rightarrow \infty} \lambda(t) S(t) e^{-\rho t} & =0,
\end{aligned}
$$

and we assume that the utility integral is bounded for any optimal path, such that $W=\int_{0}^{\infty} u\left(C^{*}(t)\right) e^{-\rho t} d t<$ $\infty$. Furthermore, both the utility function and the set of constraints are concave in states and controls, wherefore the Mangasarian sufficiency conditions are fulfilled. We now analyze the basic properties of this model before we take a look at the conditions for dynamics and sustainability. The results here are closely related to those in Heal [23] and serve as our benchmark case. We have the following lemmas (the proofs are available in the Appendix).

We shall denote the time where the social planner switches between resources by $t=T$.

Lemma 1 Given the social planner's problem (1) the non-renewable resource will be used until it becomes efficient to use the costly substitute, such that for $\forall t<T, R(t)>0$ and $M(t)=0$. Then, $\forall t \geq T, R(t)=0$ and $M(t)>0$.

Lemma 2 The social planner will choose $R(t)$ such that when he switches energy inputs at time $t=T$, then $\forall t \geq T$, we have $S(t)=0$.

Thus, Lemma 1 states that a switch between resources will occur only once, while Lemma 2 suggests that at the point in time where the switch occurs, the social planner will also fully deplete the non-renewable resource.

We basically show that a (costless) non-renewable resources should ideally be fully depleted before one moves on to a costly substitute. ${ }^{15}$

\footnotetext{
${ }^{15}$ Several modifications ought to augment this basic result. Firstly, if the extraction of non-renewable resources
} 
These Lemmas, assuming no extraction cost for the non-renewable resource, in essence then boil down to comparing relative efficiencies in production and the role that the cost of the renewable resource plays. In terms of policy questions, one would, for example, be inclined to ask whether we still have a sufficiently high stock of non-renewable resources in order to meet the energy requirements of the current production process? Does the marginal increase in production from the renewable substitute already cover its costs? For example, Canada obtains currently over $55 \%$ of its electricity from renewable energy inputs, whereas the US obtains the same amount instead from non-renewable energy (especially coal). With similar economic and tax structures these differences can thus be explained by price differences in the energy production. The country which virtually exclusively relies on renewable resources in its energy generation is Brazil with approximately $90 \%$ of its energy generation coming from renewable energy resources. This is clearly due to the fact that Brazil, firstly, has an abundance of renewable resources and, secondly, that they come much more cheaply than non-renewable inputs. Thus, given that we currently still live in a world where non-renewable resources are abundant enough to keep production sufficiently high, it is no wonder that so few countries choose to use the more costly renewable energy sources. Therefore, today, the two main factors which lead to the choice of non-renewable resources over renewable ones are simply their relative abundance and their generally lower costs.

\subsection{The role of the backstop technology}

We now study more fully the role of the backstop cost. The previous Lemmas suggest that we can be separate the control problem into two stages. The first stage with $R>0$ has been well studied (e.g. Dasgupta and Heal [13]), the link between the first and second stage has been studied in the previous section and the second stage will be studied here. Results are similar to Heal [23], but while Heal [23] uses a Cobb-Douglas production function we generalize to a Constant Elasticity of Substitution (CES) production function. The CES production function is given by $F(K, R+M)=A\left[\alpha K^{\theta}+(1-\alpha)(R+M)^{\theta}\right]^{\frac{1}{\theta}}$. Since the main problem lies in the complementarity between inputs in production, we shall only focus on the empirically more relevant case of $\theta<0$,

becomes increasingly costly the further the resource gets depleted. For example, it becomes more and more costly to mine the lower layers of coal or to withdraw oil from remote areas as in Slade [50]'s classical work which leads to an u-shape extractions path. Secondly, one could generally assume that the non-renewable resource is polluting and therefore imposes a negative externality on the agent. In these (non-exclusive) cases our results would be augmented. 
which implies complementarity between capital and the energy input. The use of the CES function then helps us in identifying the role of the complementarity between the factors of production. From $F_{R}=\gamma$ we can then solve for $M$ as a function of $K$, which gives

$$
M=\left[\frac{\alpha}{\left[\frac{\gamma}{(1-\alpha) A}\right]^{\frac{\theta}{1-\theta}}-(1-\alpha)}\right]^{\frac{1}{\theta}} K \equiv \psi^{\frac{1}{\theta}} K .
$$

Important here is the linearity between $M$ and $K$. As we can easily calculate, an interior solution requires $\gamma<(1-\alpha)^{\frac{1}{\theta}} A$. One can easily see that this condition is more likely satisfied the lower the cost of the energy substitute; the larger the share of capital in production; the better the substitution between capital and energy; and the higher the exogenously given level of technology.

We define $\Phi \equiv \alpha A[\alpha+(1-\alpha) \psi]^{\frac{1-\theta}{\theta}}, \Psi \equiv A[\alpha+(1-\alpha) \psi]^{\frac{1}{\theta}}-\gamma \psi^{\frac{1}{\theta}}$ as well as the elasticity of intertemporal substitution, $-\frac{c u_{C C}}{u_{C}} \equiv 1 / \sigma$. We find that $\forall t \geq T$, the dynamics are characterized by

$$
\begin{aligned}
C(t) & =(\Psi-\sigma(\Phi-\rho)) K_{T} e^{\sigma(\Phi-\rho)(t-T)} \\
K(t) & =K_{T} e^{\sigma(\Phi-\rho)(t-T)}
\end{aligned}
$$

Consumption will thus be a constant fraction $(\Psi-\sigma(\Phi-\rho))^{-1}$ of capital. We defined $T$ as the point in time when $\lim _{t \rightarrow T} F_{R}=\gamma$. For $\gamma$ sufficiently big we could have $T \rightarrow \infty$, whereas for $\gamma$ sufficiently small, we would have $T \rightarrow 0 .{ }^{16}$ Thus, the lower the cost of the resource substitute the earlier will we fully extract the non-renewable resource and switch to its renewable counterpart.

We are also interested in whether consumption will be positive or non-decreasing over the whole time horizon along the optimal path. A necessary condition for non-decreasing consumption is $\Phi>\rho$. Comparative static exercises show that $\Phi$ increases in $A$ and $\alpha$ but decreases in $\gamma$. Thus, if capital is more important for production or the larger the (currently) exogenously given level of technology, the more likely will consumption be non-decreasing. On the other hand, a more expensive costly substitute makes it more likely to have an unsustainable consumption path. We also obtain the standard result that a stronger preference towards today increases the likelihood of

\footnotetext{
${ }^{16}$ These results hold in the limit, with $T \rightarrow 0$ meaning that the non-renewable resource would be fully extracted at the initial point in time.
} 
unsustainable consumption.

We now simulate the model (the description of the simulations is in the Appendix) in order to understand how both $\gamma$ and the initial conditions for the state variables, in particular the initial stock of capital, affect the switching time, resource depletion and sustainability. The simulations allow us to answer the following questions: How does the cost $\gamma$ and the capital stock affect the switching time? May the non-renewable resource be depleted at a non-monotonic rate? When is consumption sustainable along the optimal path?

\subsection{Energy transition}

\section{The switching time}

The analytical results show that $F_{R}=\gamma$ is the switching condition for the non-renewable resource. It is thus evident that the size of $\gamma$ is crucial for the switching time. However, so are the initial values of the stocks $K(0)$ and $S(0)$. Indeed, the agent is required to build up a sufficient amount of capital in order to satisfy the switching condition. In terms of the stocks, it suffices to look at only one of them and we choose $K(0)$ for convenience. Figure 2 shows how the switching time is affected by changes in $\gamma$ and $K(0)$.

$>$ Figure 2 about here $<$

What we observe is that for a large enough initial stock of capital and a low enough cost of the substitute, the stock of the non-renewable resource will be used up completely in the first period. Furthermore, for a given value of $\gamma$, a smaller initial stock of the capital stock implies that the switch is postponed further. This means that a relative rich country will switch before a poor one. For a given initial stock of capital, the switching time is a monotonic, convex function of $\gamma$. Also, the smaller is the initial stock of capital the more convex the relationship between $\gamma$ and the switching time.

In terms of policy implications this suggests that, ceteris paribus, poorer countries, in terms of initial capital stock, should switch to a costly energy substitute later than richer ones. Notice, this is a pure level effect with a constant cost of the renewable resource and does not change the subsequent growth rate of consumption or capital. If one were to continue this line of thought, 
then richer countries should provide stronger incentives for using the energy substitute than poor countries. In a decentralized version of this model one would, therefore, expect richer countries to induce more incentives for the use of the costly substitute through e.g. tax and subsidy efforts. In effect, this is a behavior that we are already able to observe nowadays: mostly rich countries subsidize renewable energy inputs and thereby help to drive their costs down.

Another policy implication will be in terms of technology transfers (knowledge transfers) between rich and poor countries. If we want to reduce the gap between rich and poor countries then technology transfers imply that poor countries could benefit, in terms of their backstop costs, from the knowledge accumulation of rich countries. The results presented here are thus in favor of supported Nationally Appropriate Mitigation Actions (NAMAs), which are currently under policy discussion. ${ }^{17}$

\section{Non-monotonic depletion rate of the non-renewable resource}

In the standard Dasgupta and Heal [13] model, if the resource inputs are complements, then the non-renewable resource is monotonically depleted and its extraction tends to zero over time. In our model it is possible that the non-renewable resource is depleted in a non-monotonic fashion.

\section{$>$ Figure 3 about here $<$}

In Figure 3 we show how the non-monotonicity of the non-renewable resource depletion depends on the costs of the energy substitute. For given initial conditions $K(0)$ and $S(0)$ we notice that the higher is the cost of the substitute, the lower will be the non-renewable resource extraction. Furthermore, the non-monotonicity result does not prevail for all values of $\gamma$. The more costly the substitute the more time is needed to build up capital and therefore the longer will the nonrenewable resource be in use.

This result comes about since the policy maker firstly discounts the future and therefore uses an initially large but declining amount of the non-renewable resource, and then secondly wishes to build up a sufficient capital stock in order to satisfy the switching condition. It stands in contrast to

\footnotetext{
${ }^{17}$ For a discussion and overview of NAMAs, the interested reader is referred to Center for Clean Air Policy [7] and Osornio et al. [36].
} 
the results in Tahvonen and Salo [55], where non-renewable resources are used in an inversely ushaped manner. This happens because there is a smooth transition between non-renewables and the backstop technology. One would, however, expect a rather quick transition towards the backstop technology once this technology is productive enough in the sense that its implicit return (given by $F_{R}$ ) can cover its costs. This implicit return is, among others, depending on the substitutability between production inputs. For example, once solar and wind energy (or potentially fusion or battery systems for transportation) are sufficiently cheap, then we should see a (rather quick) shift to the backstop technologies.

\subsection{Impact on weak sustainability}

An important lesson from this model is the potential non-sustainability of consumption despite the existence of an energy substitute. It is clear now that this result crucially hinges on the costs of the energy substitute. Our benchmark calibration, in Figures 4 and 5, shows a potential variety of consumption and capital paths for an interior solution of the energy substitute for different levels of $\gamma$.

$>$ Figures 4 and 5 about here $<$

As can easily be seen, different levels of $\gamma$ can lead from endogenous growth to endogenous decline. Comparative statics show that the effect of $\gamma$ on the growth rate of capital and consumption is negative since $d \Phi / d \gamma<0$. Thus, a higher $\gamma$ implies a lower growth rate of capital and consumption. One can also calculate that $\dot{C}(t)<0$ if

$$
\gamma>(1-\alpha) A\left[\frac{1-\alpha\left(\frac{\rho}{\alpha A}\right)^{\frac{\theta}{\theta-1}}}{1-\alpha}\right]^{\frac{\theta-1}{\theta}} \equiv \bar{\gamma}
$$

and $\dot{C}(t) \geq 0$ otherwise. Comparative statics with respect to $\bar{\gamma}$ show that $d \bar{\gamma} / d \rho<0, d \bar{\gamma} / d A>0$, $d \bar{\gamma} / d \alpha<0$. If we furthermore use standard parameter configurations of $\rho=0.03, \alpha=0.3$, $A>1$, then in the neighborhood of these values we have that $d \bar{\gamma} / d \theta>0$.

Firstly, the higher $\rho$ the lower will be threshold $\bar{\gamma}$, implying that less care about the future requires an even smaller cost of the energy substitute for sustainable consumption. The parameter 
$\rho$ can, of course, capture any reason for discounting the future, from uncertainty over cultural reasons to personal characteristics of agents. The intrinsic relationship revealed here between discounting the future and the costs of the energy substitute suggests that countries with a low life-expectancy are rather likely to be unsustainable (in comparison to countries with a high lifeexpectancy) despite the existence of an energy substitute.

Secondly, for a higher total factor productivity we find that consumption may still be sustainable with larger costs of the energy substitute. This for example suggests that countries like the USA or UK, France and Germany, those countries that have a comparatively high total factor productivity, are able to substitute costly renewable energy inputs at lower costs and should therefore substitute relatively earlier than most developing countries.

Thirdly, the higher the distribution parameter of capital the lower may be the cost of the energy substitute in order to obtain a sustainable consumption path. Thus, countries which are more strongly relying on capital in their production function will be more likely to end up on with positive growth. In line with this result, we find that the easier it is to substitute energy and capital the lower may be the costs of the energy substitute for long-term growth. Indeed, what we get from this condition is that the less importance energy has for production the more likely will consumption be non-declining.

\section{The impact of learning-by-doing}

From the previous analysis we derive several results for the sustainability of consumption and for the shift between non-renewable and renewable energy inputs. The crucial parameter that we investigated was the cost of the renewable energy substitute, $\gamma$. We took $\gamma$ as constant and given. However, we also know that the costs of the energy substitutes like wind or solar energy have significantly decreased over the past years. This is mostly attributed to R\&D efforts or learning-by-doing (Arrow [3], Rosenberg [43], Bramoullé and Olson [6]). We focus on learningby-doing here for two reasons. Firstly, Tsur and Zemel [57] have already investigated the role of $\mathrm{R} \& \mathrm{D}$ in a setting similar to ours. However, what makes the analysis of learning-by-doing particularly relevant is the fact that knowledge accumulation only occurs if one uses the alternative 
energy input. This should, therefore, provide alternative incentives for the transition between the two energy inputs. Secondly, the applied literature has placed much emphasis on the so-called 'learning curves', which explain the price of the energy substitute as a function of the cumulative capacity used (McDonald and Schrattenholzer [34], Rubin [44]). Basically, an increase in the use of a technology is empirically associated with a price reduction, suggesting that firms learn how to produce more efficiently the more they use a certain technology. For example, the cost of solar cells has declined by a factor of approximately 100 since 1950 (McDonald and Schrattenholzer [34]). Similar examples can be found for virtually all types of renewable energy substitutes (see e.g. Goldemberg et al. [17], Rogner [42], Riahi et al. [41]).

In the following paragraphs we now extend the previous model to endogenous learning-bydoing based on Arrow [3]. We assume the following.

Assumption 3: We assume that $\gamma(B)>0, \forall B, \gamma_{B}<0, \gamma_{B B} \geq 0$ and $\dot{B}(t)=M(t)$. $B(t)$ therefore represents the cumulative use of $M(t)$. The more we use the energy substitute the higher the total cumulative capacity and therefore the larger the learning, implying lower costs for the future use of the energy substitute.

We, therefore, now address the question of how endogenous learning-by-doing augments some of the previous results. We are especially interested in two questions. Firstly, we wish to understand how the learning process affects energy transition, and, secondly, whether it guarantees sustainability.

\subsection{Energy transition}

Our intuition is that we should use the renewable resource earlier if we believe that learning-bydoing will reduce the costs of the substitute, but this may depend on how learning translates into cost reductions.

We now solve the previous control problem by including the endogenous learning-by-doing. The Langrangian, in current value and omitting time subscripts for convenience, of this problem then becomes

$$
\mathcal{L}=u(c)+q(F(K, R+M)-c-\gamma(B) M)-\lambda R+\phi M+\omega_{R} R+\omega_{M} M
$$


The new terms are the endogenous cost $\gamma(B)$ and $\phi M$ which represents the value of $M$ through its use in $B$. The first-order conditions lead to

$$
\begin{aligned}
u_{C} & =q, \\
\dot{\lambda} & =\rho \lambda, \\
\dot{q} & =-q F_{K}+\rho q, \\
q F_{R} & =\lambda-\omega_{R}, \\
\dot{\phi} & =q \gamma_{B} M+\rho \phi, \\
\omega_{M} & =q\left(\gamma(B)-F_{R}\right)-\phi .
\end{aligned}
$$

In the next paragraphs we collect a number of results which one can obtain from this setup.

Result 1 In the case of learning-by-doing with a costly energy substitute and for a given initial stock of capital, the more efficient the learning the earlier will the energy substitute be used.

From the Kuhn-Tucker conditions we know that $\left(q\left(\gamma(B)-F_{R}\right)-\phi\right) M=0$. Firstly, assume $\gamma=\gamma(0)$, i.e. the costs of the substitute are equal in the constant case and if no learning had yet occurred. In this case we start to use the costly substitute much earlier in the case with learning than in the case without learning, namely already when $F_{R}<\gamma(B)$, or $q\left(\gamma(B)-F_{R}\right)=\phi$, where the shadow value of $B$ is given by $\phi(t)=-\int_{t}^{\infty} q(\tau) \gamma_{B}(\tau) M(\tau) e^{-\rho(\tau-t)} d \tau>0$. Clearly, the more negative is $\gamma_{B}$, i.e. the faster the learning, the larger will be $\phi$. In other words, the more efficient is the cumulative capacity use of $M$ in reducing the costs of $M$ through learningby-doing the larger will be the shadow value of $B$. A larger shadow value of $B$ implies that the difference between $F_{R}$ and $\gamma(B)$ will be greater at the time of the transition to the renewable energy substitute. Conclusively, those countries that have good learning conditions should use the energy substitute much earlier than those that have worse learning conditions. This is shown in Figures 6 to 11, with different values of $x$ reflecting different strengths of learning (the lower is $x$ the weaker is the learning). Here we do not recover Tsur and Zemel's [56] result, which is that R\&D activities should be undertaken directly at the maximal affordable rate. We do, however, show that learning-by-doing implies that the backstop technology will be used earlier than if costs 
are exogenously given and if a country has a more efficient learning process (e.g. due to better institutions or research abilities).

\subsection{Impact on weak sustainability}

We are also interested in whether consumption is monotonic or not during transition, meaning whether the existence of an energy substitute with learning-by-doing implies sustainability. For this we shall simulate the transition period under several scenarios that only differ in their respective impacts of the learning-by-doing on the cost of the energy substitute.

Result 2 A costly energy substitute does not guarantee a monotonic consumption profile despite the possibility of learning-by-doing.

Figure 11 clearly shows that learning-by-doing may help in obtaining sustainability in comparison to an exogenously given level of $\gamma($ case $x=0)$. However, we also see that consumption can be non-monotonic. Since we start to use the energy substitute now earlier, this implies that we reduce the capital stock since the substitute is too expensive. However, with a higher capacity use the agent learns and therefore the costs of the energy substitute diminish, which eventually leads to a situation where the costs may be low enough to imply endogenous growth.

$>$ Figures 6 to 11 about here $<$

As a consequence, we see an n-shaped consumption profile. Early generations benefit from the increasing use of the non-renewable resource. Later generations see declining levels of capital and therefore consumption since the stock of non-renewable resources has been used by the previous generations and they face costs of the energy substitute that are too high to keep capital at the current level. Finally, generations that come even later in time may see increasing consumption again if learning-by-doing is able to sufficiently reduce the costs of the energy input. In contrast, under learning-by-doing that is too weak to sufficiently reduce costs, these later generations would also see a declining consumption profile. 


\section{$5 \quad$ Tying in with integrated assessment models}

In this section we discuss our results in the light of simulations done in the integrated assessment model (IAM) literature. We focus on a selection of recent articles, namely Messner [35], Grübler and Messner [21], Manne and Richels [33], Rao et al. [40], and van der Zwaan et al. [60]. For surveys on further integrated assessment models that deal with technical change we refer the reader to Löschel [31] and Kahouli-Brahmi [30].

Messner [35] introduces learning-by-doing in a bottom-up IAM called MESSAGE. She links the investment costs of alternative energies (wind, solar) to their cumulative installed capacity. Her main result is that learning-by-doing leads to an earlier adoption of the alternative energies, with those energies also taking up a larger share of overall energy production. This is directly related to our Result 1, where we show that learning-by-doing leads to an earlier use of the alternative energy. ${ }^{18}$ Grübler and Messner [21] extend the previous article by adding a carbon cycle model. They observe that in this case, learning-by-doing leads to fewer emissions compared to the exogenous cost case. This result is recuperated in Schumacher [47], who introduces the risk of a catastrophe with increasing extraction of the non-renewable resource in the current model. In effect, in this case the non-renewable resource will not be fully extracted in order to leave some carbon in the ground. van der Zwaan et al. [60] develop a bottom-down model dubbed DEMETER. Their main result is similar to what we presented here. Firstly, the alternative energies present the most important option for emission reductions. Secondly, learning-by-doing leads to earlier investments in the alternative energies. Conclusively, the results that we obtained in the previous sections do not (qualitatively) change in the standard IAM. The main qualitative change arises with the introduction of catastrophic risk as in Schumacher [47], where the use of non-renewable resources induces a permanently higher risk of a catastrophe and may lead to some resources optimally left in the ground.

Manne and Richels [33] develop upon the bottom-up MERGE model by introducing learningby-doing and investigate the impact thereof on the timing and costs of emissions abatement. They find that learning-by-doing may influence the transition time to the alternative energy resource depending on the strength of the learning. This is precisely what we argue in Result 1 . The

\footnotetext{
${ }^{18}$ This result requires that the initial level of $\gamma$ is equal in both the exogenous and the learning-by-doing case.
} 
shadow value of the cumulative installed capacity increases, ceteris paribus, with the effectiveness of the learning-by-doing. Therefore, the more effective the learning-by-doing the earlier will we substitute to the alternative energies.

Rao et al. [40] develop upon the IAM model MESSAGE by introducing learning-by-doing. They find that learning-by-doing is not not enough to stabilize greenhouse gas emissions and that climate policies are necessary, too. Clearly, in the model presented here, the non-renewable resources will always be fully extracted. Learning-by-doing will even lead to a higher extraction rate. In consequence, without taking the costs from greenhouse gas emissions into account, the model predicts a more drastic evolution of the carbon concentration. This is in line with the results presented in Manne and Richels [33], who find that, in the medium run, emissions are lower without learning-by-doing. If one, however, takes the costs of the carbon emissions into account as is done in Schumacher [47], then this model would predict that some carbon may be optimally left in the grounds. Which model is more applicable in practice obviously depends on the policy maker and the international decision process.

Clearly, one message to take away from this section and the analysis of the model above is that the literature, up to now, did not sufficiently investigate the leading role that rich countries can play. One of our results was that richer countries should shift to the alternative energy earlier than poorer countries. If one assumes learning to be an international process, this would imply that an early energy shift of richer countries also benefits the poorer countries in the sense that they will observe decreasing costs of their alternative energies. This, in turn, will also help them to shift more quickly to the energy substitute. As a bonus, this will keep global emissions lower. In addition, this could help some poor countries to end up on a sustainable path that they, due to their low capital stock, otherwise would not have attained. Hence, in case the knowledge from learning is non-rival and non-exclusive, then this would induce the double-dividend of both potential sustainability and lower carbon emissions for poor countries. A policy-relevant tool should then be Nationally Appropriate Mitigation Action (see Center for Clean Air Policy [7]). 


\section{Conclusion}

Considering our analysis, we recover, in a slightly different setting, Heal's [23] result, namely that it is never optimal to use both non-renewable resources and the costly renewable resources over an extended period of time and the non-renewable resource should be exhausted when one shifts to the backstop. We then study more deeply the role of the backstop cost for transition and sustainability. We find that the switching time increases with the cost of substitute and decreases with the initial capital stock. Therefore, a poorer country should shift towards the costly substitute later than a richer one.

Moreover, the non-renewable resource may be depleted non-monotonically (u-shaped extraction). This result stands in contrast to Tahvonen and Salo [55], who, in a model with increasing extraction costs and increasing marginal costs for the backstop, find an inversely $\mathrm{u}$-shaped extraction of the non-renewable resource. The difference comes about since in their model non-renewable and renewable resources are used simultaneously even over a longer period of time while our assumptions imply that both resources are not used simultaneously. We believe that both results make sense depending on what kind of backstop technology one has in mind. Once mankind manages to control fusion at a low cost then it seems reasonable to argue that, within a very short period of time, most of our energy production will come from fusion and the results of our model should apply. If we were to think about hydroenergy as the backstop technology, then it would be reasonable to assume increasing marginal costs for this backstop and we would most likely see a simultaneous use of non-renewables and the backstop.

We, furthermore, show that the existence of a backstop technology is not sufficient to insure sustainable consumption along the optimal path. In fact, we show that countries are inclined to rely on the non-renewable resource and when it is finally depleted they might be faced with a cost of the energy substitute which is too high for sustainable consumption along the optimal path.

Since we know that various kinds of backstop technologies are subject to the so-called 'learning curves', we then study the previous results under learning-by-doing. With learning-by-doing the energy substitute will, in general, be used earlier than if costs are exogenously given. This opens up a great deal of possible policy implications. For example, firms that are producing in a 
competitive structure may not be able to invest in a technology that is too costly now and, therefore, when the non-renewable resources are depleted, the substitutes may be too expensive. This point gives support to the current subsidy policies that we see everywhere. Helping firms to bring energy substitutes on the market implies that, when the non-renewable resources will be finally used up, the substitutes may be cheap enough to guarantee long-run growth.

We also argued that if countries were to interact in a world where ideas are non-rival (see e.g. Jones [28]) and rich countries would, indeed, act optimally and shift towards the backstop earlier than poor countries, then this would lead to a positive externality on the backstop costs in poor countries through technological spillovers. This will also induce poor countries to adopt the backstop technology earlier than they otherwise would. Early adoption of backstop technologies by the rich nations coupled with technology spillovers, in the form of e.g. NAMAs, are, thus, a useful aid allowing poor countries to make use of a backstop technology that otherwise might be too expensive for them.

Though it is more likely that learning-by-doing may lead to endogenous growth due to its effect on the costs of the energy substitute, during the transition period consumption may be growing non-monotonically. This comes about since the backstop technology might initially be too expensive to allow for sustainable consumption along the optimal path. The increasing use of the backstop technology will, however, lead to cost reductions over time. In case these cost reductions are sufficiently large, then the backstop technology will allow non-declining consumption along the optimal path. This pattern may lead to a non-sustainable path in the sense of Sustainable Development defined above, where later generations may be forced to rely on expensive energy substitutes once the non-renewable resources are exhausted. This gives rise to potential concerns of intergenerational equity and would, for example, the question the use solely relying on learning-by-doing in order to bring the costs of alternative energies down.

In the discussions above we abstracted from the issues raised in e.g. Heal [24] and others. Basically, alternative energy resources still face problems of intermittency, of uncertainty as to whether one actually invests in the good technology (compared to one that might turn out to be more efficient later), and many countries also face problems of actually being able to tap those alternative resources to a sufficient extent. Some countries have little sun, other little wind, yet 
others lack enough fast-flowing water. These country-specific physical constraints are unlikely to be overcome and potentially limit a country's means of deriving sufficient energy from these alternatives. Clearly, our work applies less to countries that face these constraints than to those that have the fortunate of a good geo-energy location.

Future research could, therefore, address the following points. Firstly, how does a decentralized economy respond to the possibility of learning-by-doing? What is a useful government policy in this setting? Indeed, without government intervention we would not see a firm investing in a technology that is currently too expensive. In a completely decentralized model, energy producing firms will not make use of the learning-by-doing possibility. We would, therefore, expect that only government intervention in the form of e.g. price subsidies will lead to an optimal earlier adoption of the backstop technology by firms. This, obviously, only applies to the case where one believes that learning-by-doing is the most significant factor leading to cost reductions. If $R \& D$ were believed to reduce costs more efficiently, then a monopolistic market should be enough to lead to an earlier adoption and government intervention might only need to focus on whether too much or too little $R \& D$ is undertaken.

\section{Appendix}

\section{Procedure for Simulations}

We use the following configurations for the simulations. Simulations are done over a horizon of 250 time periods. Utility is of the constant relative risk aversion type with $\sigma=0.5$. Production is a CES function with a distribution parameter of $\alpha=0.33$, total factor productivity of $A=1$. In the baseline cases $\gamma$ is kept constant and varied between 1.3 and 1.8. When $\gamma$ is endogenous we choose the functional form $\left(\gamma_{\min }+1 /(1+x B(t))\right)$. We assume gmin $=0.4$ and vary $x$ from 0 to 0.0014. Initial conditions are $S(0)=200$ and $K(0)=0.2$, the discount rate is chosen at $\rho=0.03$ and the elasticity of substitution in the production function is $\theta=-0.4$.

\section{Proof of Lemma 1}

We take the case of $R>0$ and $M=0$. This implies $q F_{R}=\lambda, q\left(F_{R}-\gamma\right)=-\omega_{M}$, and therefore 
$F_{R}<\gamma$ and we obtain a Hotelling rule, $\hat{F}_{R}=F_{K}$. Since this implies that $F_{R}>0$, there exists a $T$ s.th. $\lim _{t \rightarrow T} F_{R}=\gamma$, which implies that $M>0$. The next case is $R=0$ and $M>0$. Again, from the Kuhn-Tucker condition we calculate that $q F_{R}+\omega_{R}=\lambda$ and $F_{R}=\gamma$, which implies $q \gamma<\lambda$. Since $\lambda>q$, we know $\exists T \geq 0$ s.th. $q \gamma<\lambda$ and therefore $R=0, M>0, \forall t>T$. Assume that $R>0$ and $M>0$. This implies $q F_{R}=\lambda$ and $F_{R}=\gamma$, which implies $q \gamma=\lambda$. If $q \gamma=\lambda$, then both resources may be used at the same time. In a continuous time setting this may only hold at a degenerate point in time since $q \gamma=\lambda$ implies that $\dot{q} / q=\dot{\lambda} / \lambda$. This can only be satisfied if $F_{K}=0$, thus if $K \rightarrow \infty$, which implies a contradiction.

\section{Proof of Lemma 2}

Proof by contradiction. Assume $\int_{0}^{T} R(t) d t<S(0)$. Since $R(t)=0 \forall t \geq T$, then $S(T)>0$. But by the transversality condition $\lim _{t \rightarrow \infty} \lambda(t) S(t) e^{-\rho t}=0$, and since $\lambda(t)=\lambda(0) e^{\rho t}$ where $\lambda(0)>0$, this would imply $\lim _{t \rightarrow \infty} \lambda(t) S(t)=\lambda(0) S(T)>0$. Therefore we have a contradiction which implies $\forall t>T, S(t)=0$.

\section{References}

[1] ANAND, S., AND SEN, A. Human Development and Economic Sustainability. Word Development 28, 12 (2000), 2029-2049.

[2] ARONSSON T., K. BACKLUND AND K.G. LÖFGREN. Nuclear power, externalities and non-standard pigouvian taxes. Environmental and Resource Economics 11, 2 (1998), 177195.

[3] ARROW, K. The economic implications of learning by doing. Review of Economic Studies 29, 3 (1962), 155-173.

[4] AYONG LE KAMA, A., AND SCHUBERT, K. Growth, Environment and Uncertain Future Preferences. Environmental and Resource Economics 28, 1 (2004), 31-53. 
[5] BOUCEKKINE, R., AND POMMERET, A. Energy saving technical progress and optimal capital stock: the role of embodiment. Economic Modelling 21, 3 (2004), 429-444.

[6] BRAMOULLÉ, Y., AND OLSON, L. Allocation of pollution abatement under learning by doing. Journal of Public Economics 89, 9-10 (2005), 1935-1960.

[7] CENTER FOR CLEAN AIR POLICY. Nationally appropriate mitigation actions by developing countries: Architecture and key issues. Washington, D.C. (December 1, 2009).

[8] CHAKRAVORTY, U., ROUMASSET, J., AND TSE, K. Endogenous substitution among energy resources and global warming. Journal of Political Economy 105, 6 (1997), 12011234.

[9] CHANG, Y., AND YONG, J. Differing perspectives of major oil firms on future energy developments: An illustrative framework. Energy Policy 35, 11 (2007), 5466-5480.

[10] CLARK, R. The relationship between price and marginal extraction cost for a resource with a backstop technology: Comment. The Bell Journal of Economics 9, 1 (1978), 292-293.

[11] DALY, H.E. AND COBB, J.B. AND COBB, C.W. For the common good: Redirecting the economy toward community, the environment, and a sustainable future. Beacon Pr, 1994.

[12] DASGUPTA, P. Discounting climate change. Journal of Risk and Uncertainty 37, 2 (2008), $141-169$.

[13] DASGUPTA, P., AND HEAL, G. The optimal depletion of exhaustible resources. The Review of Economic Studies 41 (1974), 3-28.

[14] DASGUPTA, P., AND HEAL, G. Economic theory and exhaustible resources. Cambridge University Press, 1979.

[15] ENDRESS, L., AND ROUMASSET, J. Golden Rules for sustainable resource management. Economic Record 70, 210 (1994), 267-277. 
[16] GJERDE J., GREPPERUD, S., AND KVERNDOKK, S. Optimal climate policy under the possibility of a catastrophe. Environmental and Resource Economics 21, 3-4 (1999), 289317.

[17] GOLDEMBERG, J., COELHO, S., NASTARI, P., AND LUCON, O. Ethanol learning curve: the Brazilian experience. Biomass and Bioenergy 26, 3 (2004), 301-304.

[18] GRIMAUD, A., AND ROUGÉ , L. Non-renewable resources and growth with vertical innovations: optimum, equilibrium and economic policies. Journal of Environmental Economics and Management 45, 2 (2003), 433-453.

[19] GRIMAUD, A., AND ROUGÉ , L. Polluting non-renewable resources, innovation and growth: welfare and environmental policy. Resource and Energy Economics 27, 2 (2005), $109-129$.

[20] GROWIEC, J., AND SCHUMACHER, I. On technical change in the elasticities of resource inputs. Resources Policy 33, 4 (2008), 210-221.

[21] GRÜBLER, A., AND MESSNER, S. Technological change and the timing of mitigation measures. Energy Economics 20, 5-6 (1998), 495-512.

[22] HANSON, D. Increasing extraction costs and resource prices: Some further results. The Bell Journal of Economics 11, 1 (1980), 335-342.

[23] HEAL, G. The relationship between price and extraction cost for a resource with a backstop technology. The Bell Journal of Economics 7, 2 (1976), 371-378.

[24] HEAL, G. Reflections the economics of renewable energy in the united states. Review of Environmental Economics and Policy 4, 1 (2010), 139.

[25] HOTELLING, H. The Economics of Exhaustible Resources. The Journal of Political Economy 39, 2 (1931), 137-175.

[26] INTERNATIONAL ATOMIC ENERGY AGENCY. Annual Report 2001. Organization for Economic Co-operation and Development, 2001. 
[27] JOHN, A., AND PECCHENINO, R. An overlapping generations model of growth and the environment. The Economic Journal 104, 427 (1994), 1393-1410.

[28] JONES, C. I. Sources of U.S. Economic Growth in a World of Ideas. The American Economic Review 92, 1 (2002), 220-239.

[29] JUST, R., NETANYAHU, S., AND OLSON, L. Depletion of natural resources, technological uncertainty, and the adoption of technological substitutes. Resource and Energy Economics 27, 2 (2005), 91-108.

[30] KAHOULI-BRAHMI, S. Technological learning in energyenvironmenteconomy modelling: A survey. energy policy 36, 1 (2008), 138-162.

[31] LÖSCHEL, A. Technological change in economic models of environmental policy: a survey. Ecological Economics 43, 2-3 (2002), 105-126.

[32] MANDIL, C. World Energy Outlook 2004. International Energy Agency, 2008.

[33] MANNE, A., AND RICHELS, R. The impact of learning-by-doing on the timing and costs of co2 abatement. Energy Economics 26, 4 (2004), 603-619.

[34] MCDONALD, A., AND SCHRATTENHOLZER, L. Learning rates for energy technologies. Energy policy 29, 4 (2001), 255-261.

[35] MESSNER, S. Endogenized technological learning in an energy systems model. Journal of Evolutionary Economics 7, 3 (1997), 291-313.

[36] OSORNIO, J. P., SCHUMACHER, I. AND K. DESPOTA. Global Corruption Report: Climate Change. Earthscan, 2011, ch. Measuring, Reporting and Verification of NAMAs and their Support: Considering Capacity, Corruption and Commitments, pp. 120-129.

[37] PEREZ-BARAHONA, A., AND ZOU, B. A comparative study of energy saving technical progress in a vintage capital model. Resource and Energy Economics 28, 2 (2006), 181-191.

[38] PEZZEY, J. Sustainability constraints versus optimality versus intertemporal concern, and axioms versus data. Land Economics 73, 4 (1997), 448-466. 
[39] POWELL, S., AND OREN, S. Transition to non-depletable energy: social planning and market models of capacity expansion. Operations Research 37, 3 (1989), 373-383.

[40] RAO, S., KEPPO, I., AND RIAHI, K. Importance of technological change and spillovers in long-term climate policy. The Energy Journal 1 (2006), 123-140.

[41] RIAHI, K., RUBIN, E., TAYLOR, M., SCHRATTENHOLZER, L., AND HOUNSHELL, D. Technological learning for carbon capture and sequestration technologies. Energy Economics 26, 4 (2004), 539-564.

[42] ROGNER, H. Hydrogen technologies and the technology learning curve. International Journal of Hydrogen Energy 23, 9 (1998), 833-840.

[43] ROSENBERG, N. Inside the black box: technology and economics. Cambridge University Press, 1982.

[44] RUBIN, E., TAYLOR, M., YEH, S., AND HOUNSHELL, D. Learning curves for environmental technology and their importance for climate policy analysis. Energy 29, 9-10 (2004), $1551-1559$.

[45] SCHMALENSEE, R. AND STOKER, T.M. AND JUDSON, R.A. World carbon dioxide emissions: 1950-2050. Review of Economics and Statistics 80, 1 (1998), 15-27.

[46] SCHOU, P. Polluting non-renewable resources and growth. Environmental and Resource Economics 16, 2 (2000), 211-227.

[47] SCHUMACHER, I. When should we stop extracting non-renewable resources? Macroeconomic Dynamics 15, 04 (2011), 495-512.

[48] SCHUMACHER, I., AND ZOU, B. Pollution perception: A challenge for intergenerational equity. Journal of Environmental Economics and Management 55, 3 (2008), 296-309.

[49] SHAFIEE, S., AND TOPAL, E. When will fossil fuel reserves be diminished? Energy Policy 37, 1 (2009), 181-189. 
[50] SLADE, M. Trends in natural-resource commodity prices: an analysis of the time domain. Journal of Environmental Economics and Management 9, 2 (1982), 122-137.

[51] SOLOW, R. Intergenerational equity and exhaustible resources. The Review of Economic Studies 41 (1974), 29-45.

[52] SOLOW, R. The economics of resources or the resources of economics. The American Economic Review 64, 2 (1974), 1-14.

[53] STERN, N. The economics of climate change: the Stern review. Cambridge University Press, 2007.

[54] TAHVONEN, O. Fossil fuels, stock externalities, and backstop technology. The Canadian Journal of Economics/Revue canadienne d'Economique 30, 4a (1997), 855-874.

[55] TAHVONEN, O., AND SALO, S. Economic growth and transitions between renewable and nonrenewable energy resources. European Economic Review 45, 8 (2001), 1379-1398.

[56] TSUR, Y., AND ZEMEL, A. Optimal transition to backstop substitutes for nonrenewable resources. Journal of Economic Dynamics and Control 27, 4 (2003), 551-572.

[57] TSUR, Y., AND ZEMEL, A. Scarcity, growth and R\&D. Journal of Environmental Economics and Management 49, 3 (2005), 484-499.

[58] TSUR, Y., AND ZEMEL, A. Regulating environmental threats. Environmental and Resource Economics 39, 3 (2008), 297-310.

[59] TSUR, Y., AND ZEMEL, A. Endogenous Discounting and Climate Policy. Environmental and Resource Economics 44, 4 (2009), 507-520.

[60] VAN DER ZWAAN, B.C.C. AND GERLAGH, R. AND KLAASSEN, G. AND SCHRATTENHOLZER, L. Endogenous technological change in climate change modelling. Energy Economics 24, 1 (2002), 1-19. 
[61] WIRL, F. Monopolistic resource extraction and limit pricing: The market penetration of competitively produced synfuels. Environmental and Resource Economics 1, 2 (1991), 157178. 


\section{Figures}

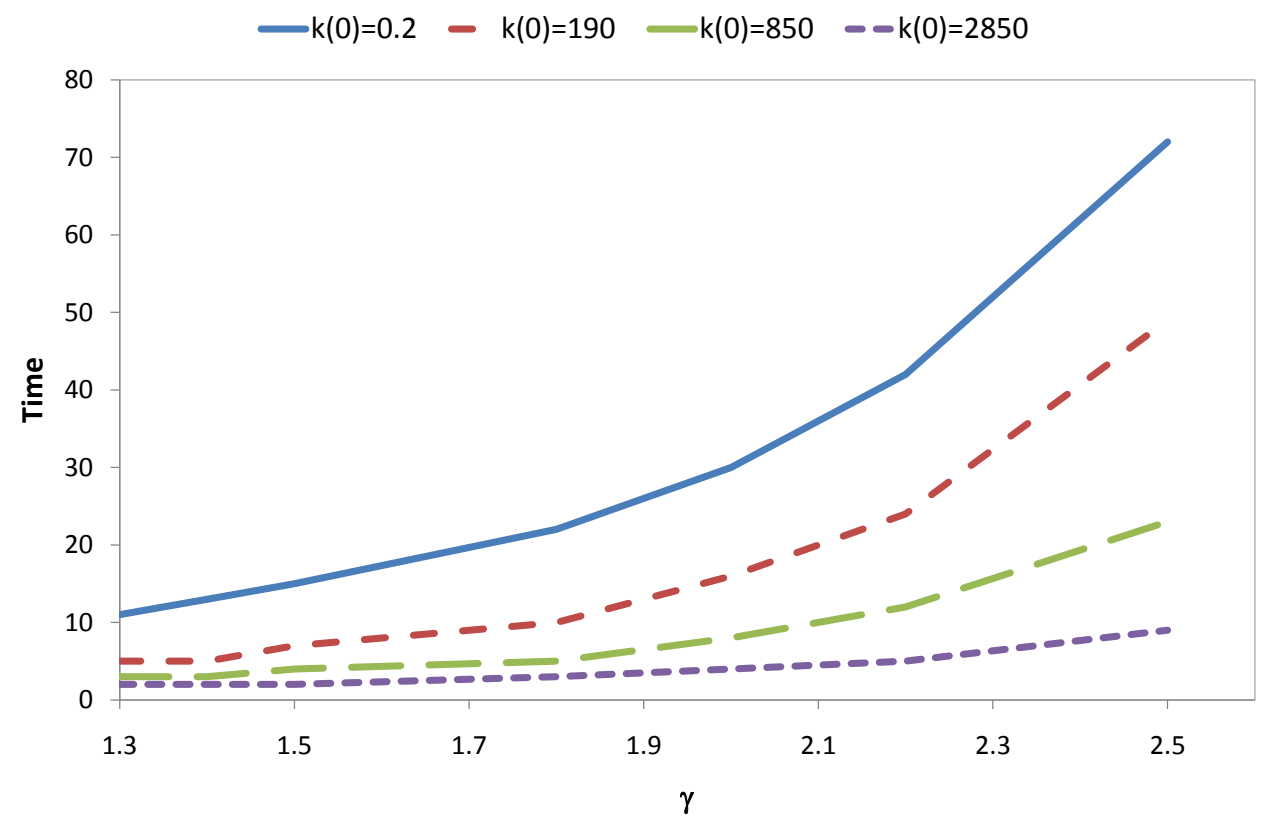

Figure 2: The switching time as a function of $\gamma$ and $K(0)$ 


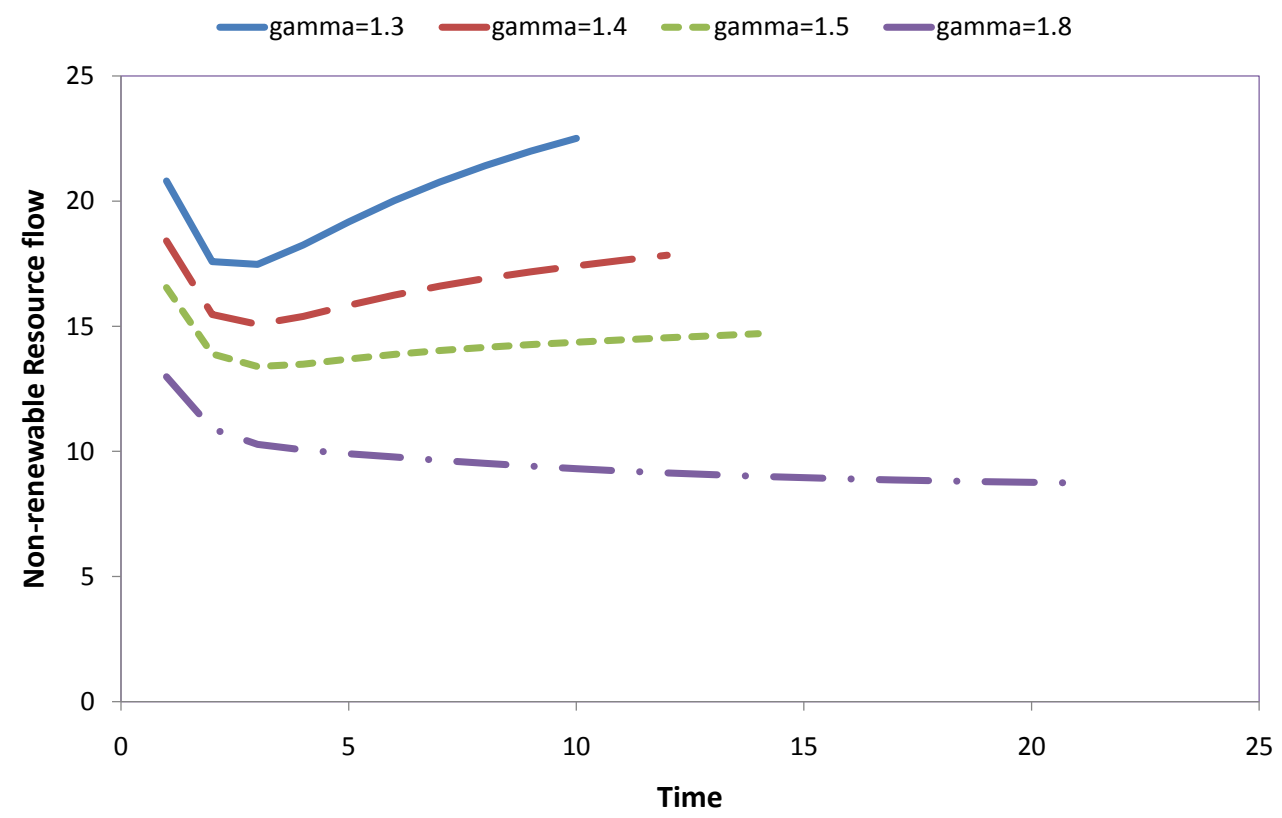

Figure 3: Non-renewable resource flow

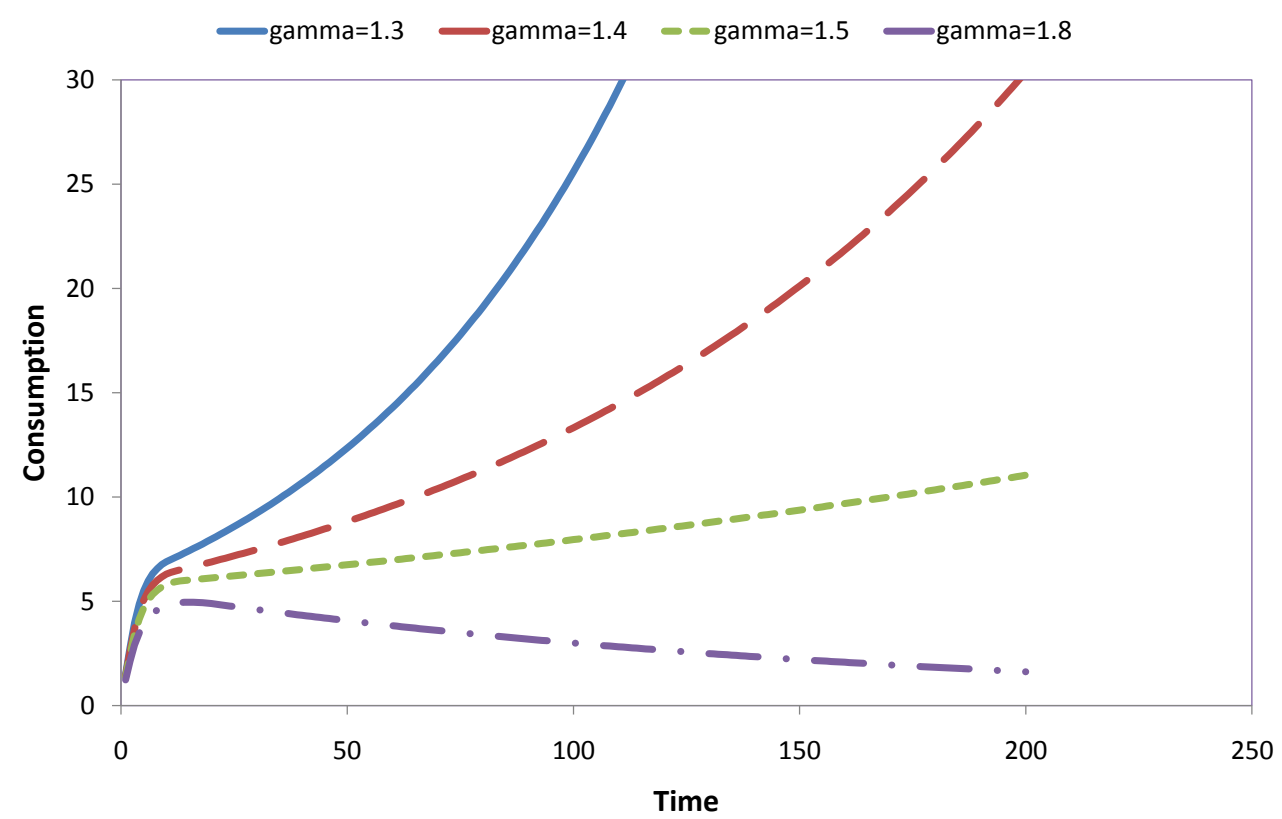

Figure 4: Evolution of consumption 


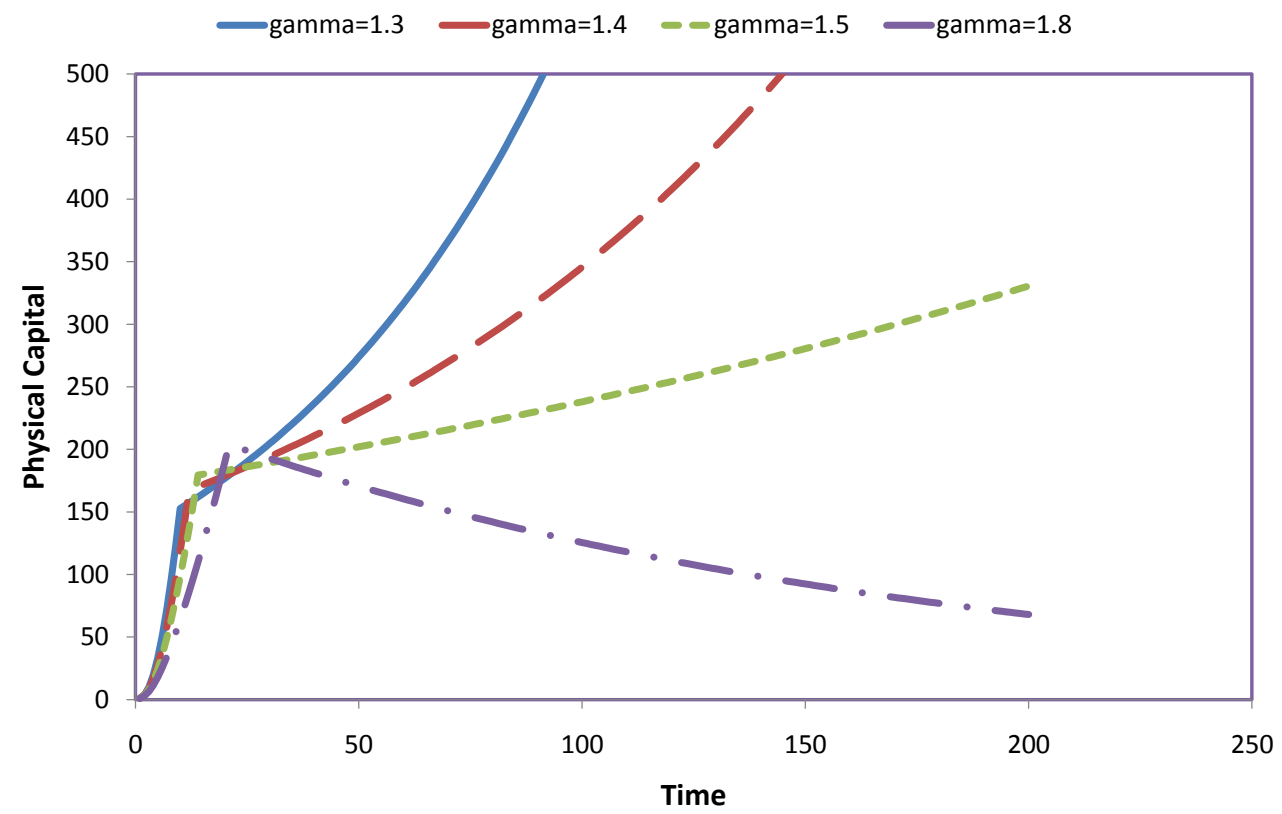

Figure 5: Evolution of the capital stock

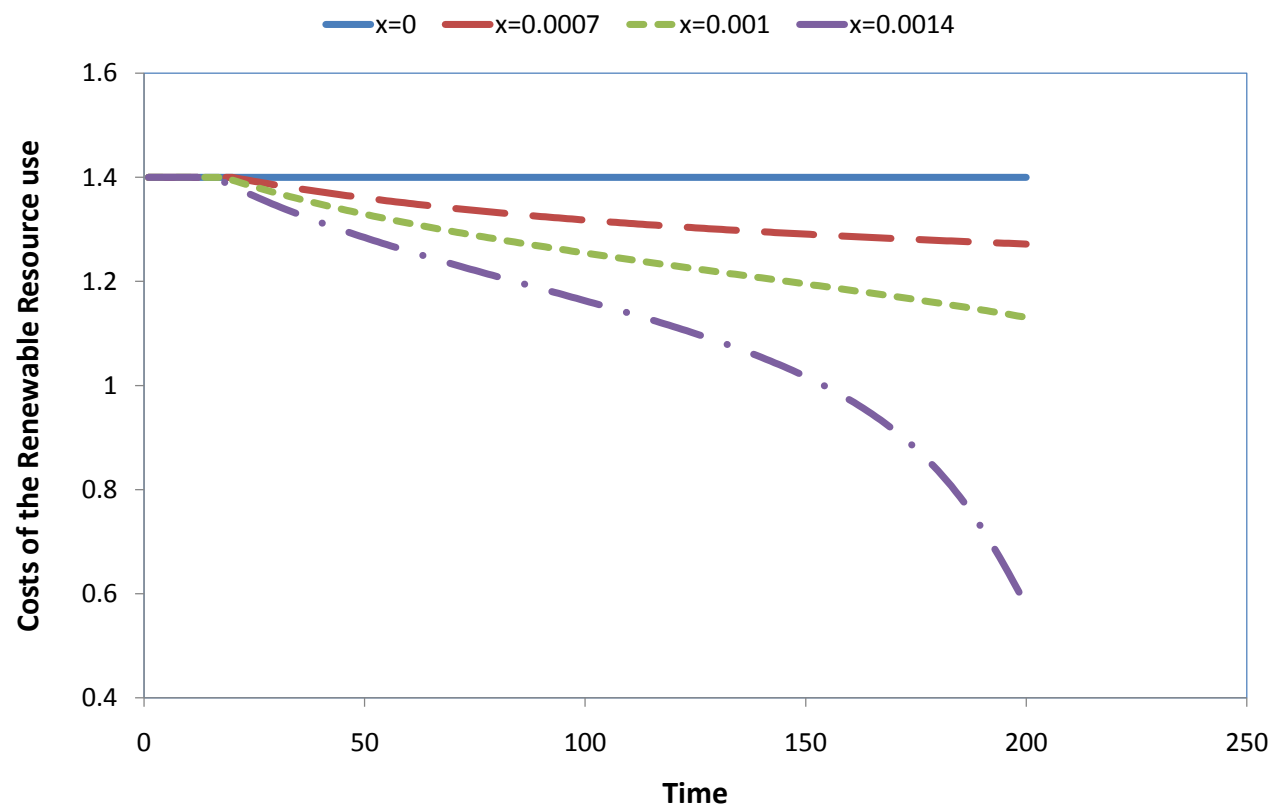

Figure 6: Costs of the energy substitute under learning-by-doing 


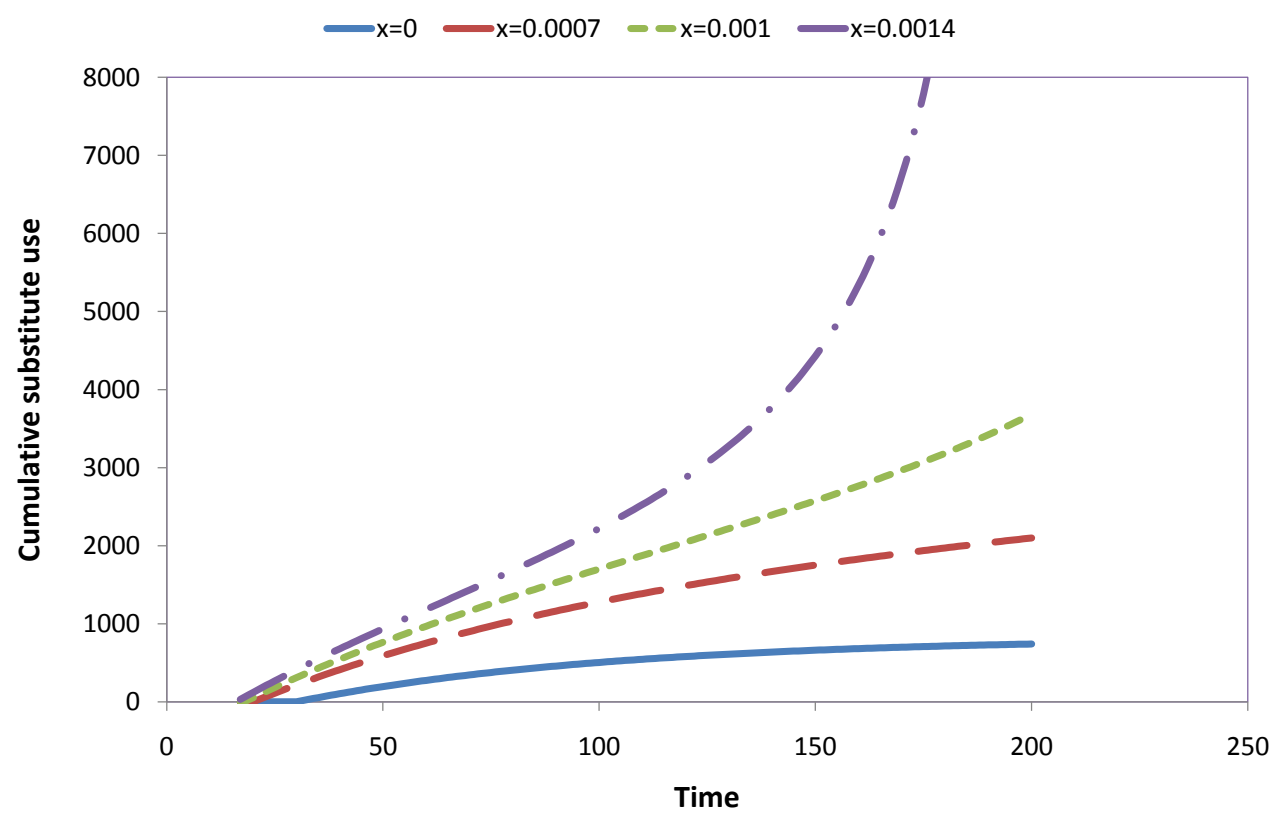

Figure 7: Cumulative substitute use under learning-by-doing

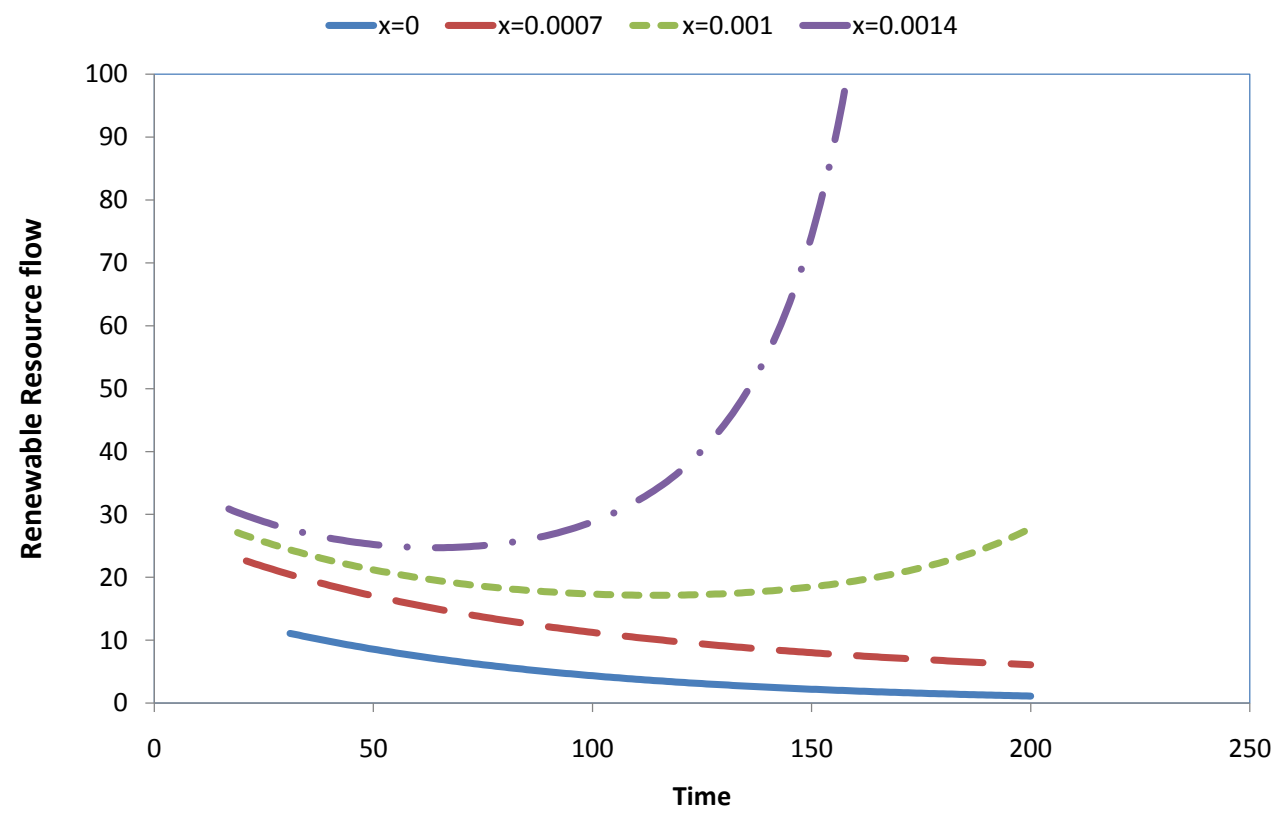

Figure 8: Renewable resource under learning-by-doing 


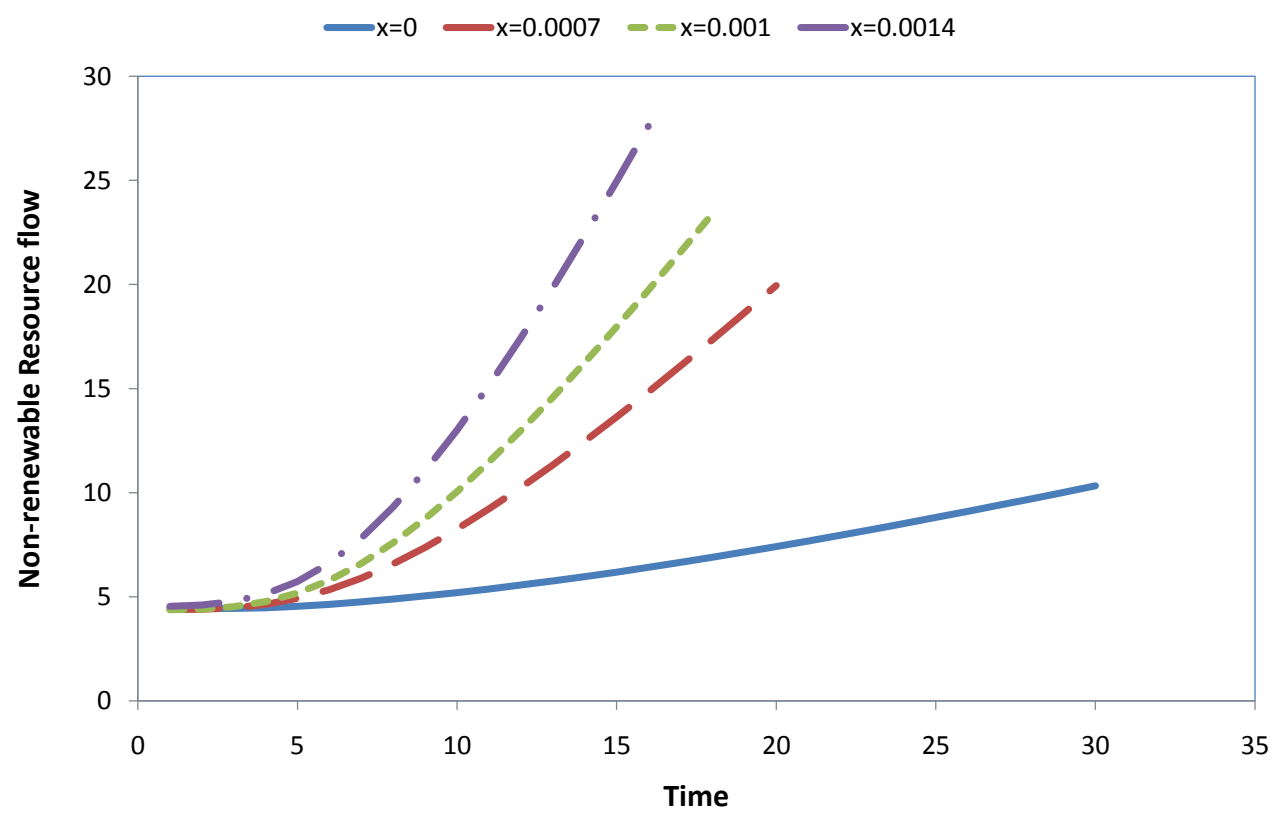

Figure 9: Non-renewable resource under learning-by-doing

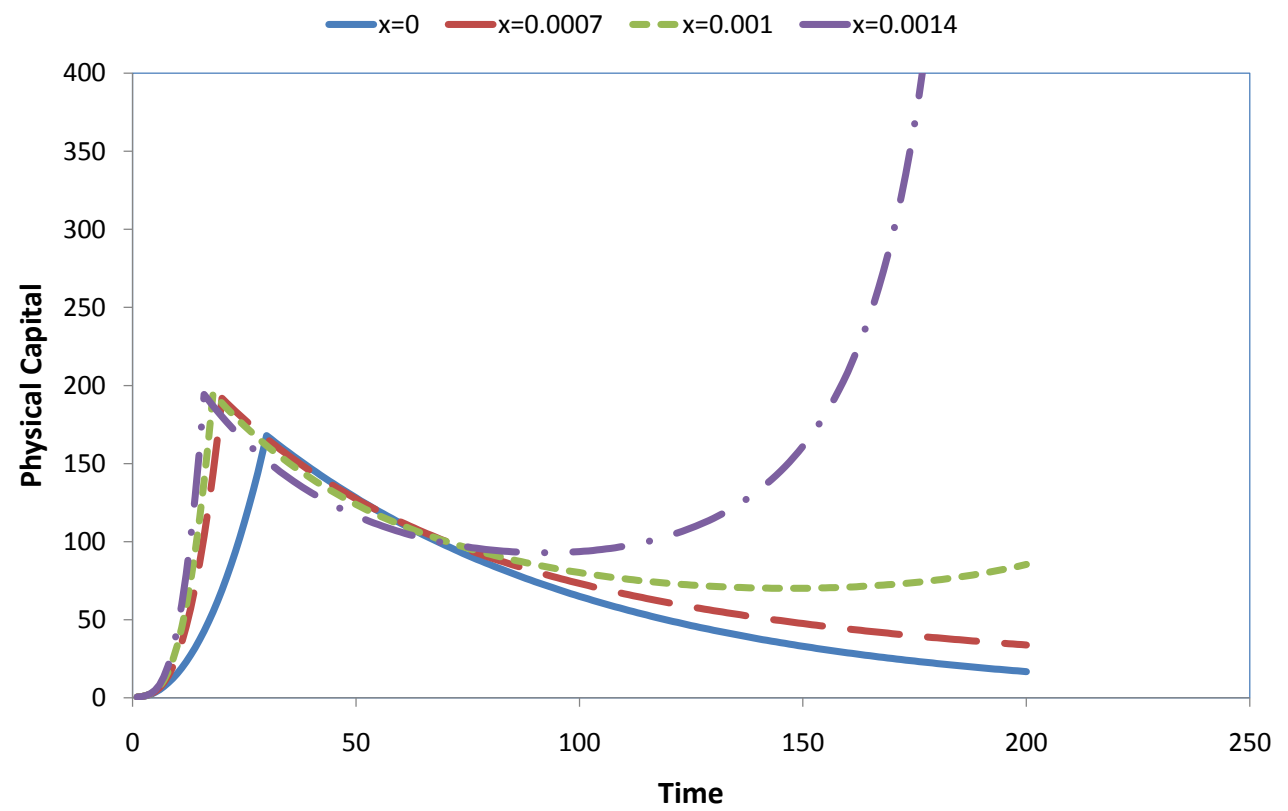

Figure 10: Capital stock under learning-by-doing 


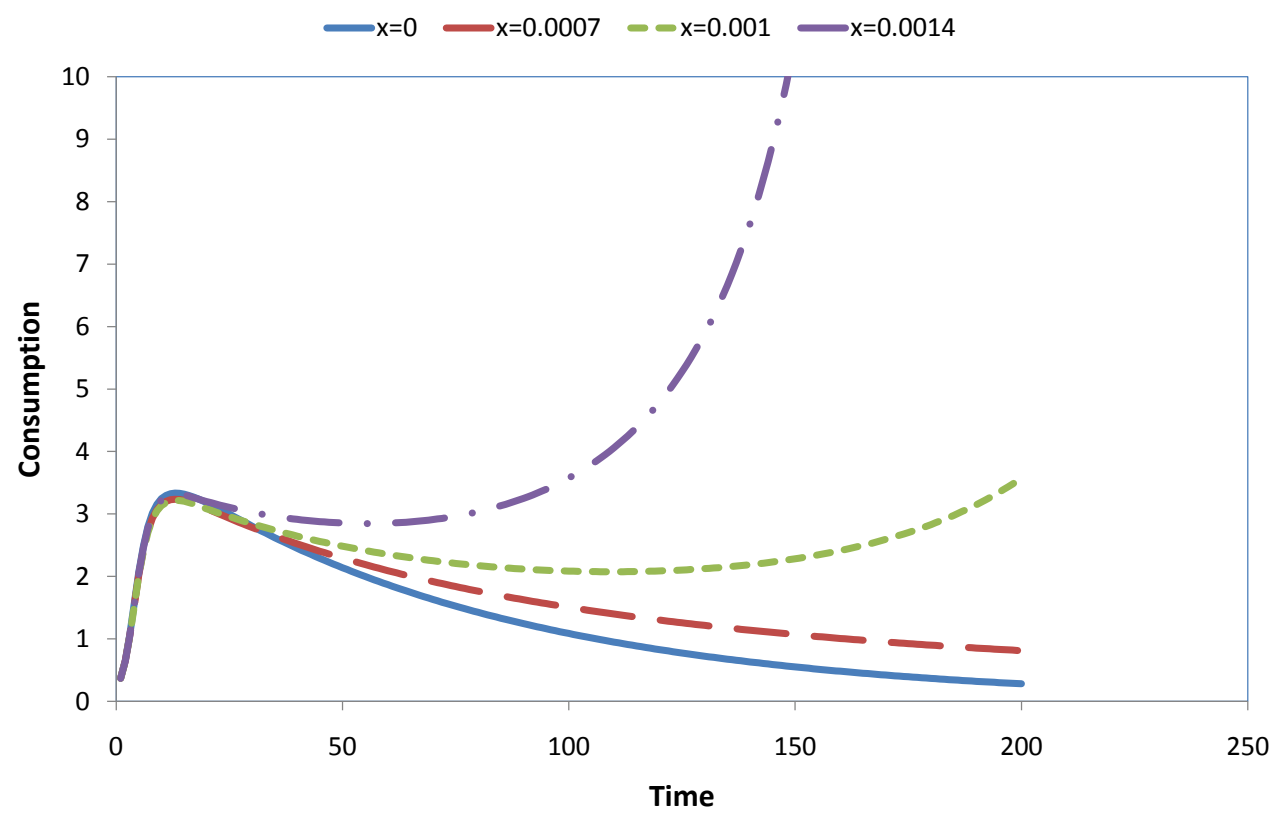

Figure 11: Consumption under learning-by-doing 